\title{
Microstructural evolution and Mechanical Properties of a Newly Developed $\mathrm{Ti}_{2} \mathrm{AlNb}$-based alloy
}

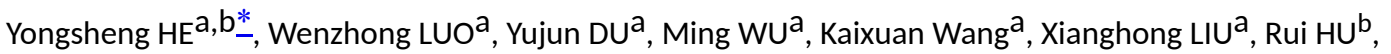 \\ a. Western Superconducting Technologies Co., Ltd, Shan Xi Province Engineering Laboratory for Aerial Material, Xi'an 710018, \\ China
}

b. State Key Laboratory of Solidification Processing, Northwestern Polytechnical University, Xi'an 710072, China

\begin{abstract}
The effects of the microstructure on the tensile and creep properties of the alloy at room temperature and high temperature were investigated by controlling the microstructures of the alloy by different hot working processes. It is found that the lath microstructure obtained by forging in $\mathrm{B} 2$ single phase zone has high tensile strength. The tensile strength is $1188 \mathrm{MPa}$ at room temperature and $950 \mathrm{MPa}$ at high temperature. The equiaxed structure obtained by forging in $\mathrm{O}+\mathrm{B} 2$ phase region has the characteristics of high plasticity, creep resistance and low tensile strength. The elongation at room temperature is $9.0 \%$, and the elongation at high temperature is $36 \%$. The ambient temperature, high temperature tensile properties of the dual microstructure obtained by forging in the three-phase zone of $\mathrm{a}_{2}+\mathrm{O}+\mathrm{B} 2$ are between the lath and the equiaxed microstructure.
\end{abstract}

Keywords: $\mathrm{Ti}_{2} \mathrm{AlNb}$-based alloy; Microstructure; Mechanical Properties

\section{Introduction}

Due to higher strength-to-density ratio, better room-temperature ductility and more reasonable elevated temperature mechanical properties than conventional titanium aluminides [1-4], $\mathrm{Ti}_{2} \mathrm{AINb}$ based alloy has been considered as potential structural materials for aircraft engine application at elevated temperature. However, their poor oxidation resistance at high temperatures of above $750^{\circ} \mathrm{C}$ [5] and insufficient elevated-temperature strength [6-7] still limit their wide application. In the resent years, Efforts have been made to improve the high temperature oxidation resistance by adding alloying elements to $\mathrm{Ti}_{2} \mathrm{AINb}$ based alloys. The previous research [8-11] have been found that multiple additions of $\mathrm{Mo}, \mathrm{V}, \mathrm{Zr}$ and $\mathrm{Si}$ are effective to improve oxidation resistance and creep strength. It was reported a $\mathrm{Ti}_{2} \mathrm{AlNb}$-based alloy with $\mathrm{Ti}-22 \mathrm{Al}-25 \mathrm{Nb}-1 \mathrm{Mo}-1 \mathrm{~V}-1 \mathrm{Zr}-0.2 \mathrm{Si}$ showing excellent high temperature oxidation resistance. the weight gain of $\mathrm{Ti}_{2} \mathrm{AlNb}$-based alloy oxidized at $850^{\circ} \mathrm{C}$ for $100 \mathrm{~h}$ was only $0.41 \mathrm{mg} / \mathrm{cm}^{-2}$ [12]. And the creep strain at $650^{\circ} \mathrm{C} / 150 \mathrm{MPa}$ is only $0.12 \%$ under $100 \mathrm{~h}$ loading [13]. However, it exhibits poor room temperature tensile elongation of less than $5 \%$.

The mechanical properties of the $\mathrm{Ti}_{2} \mathrm{AlNb}$ alloys are affected extensively by their microstructures [14]. However, phase equilibria and microstructural evolution in orthorhombic alloys are complicated. The volume fraction, size, and morphology of the constituent phases are dependent on the thermal processing and the heat treatment $[15,16]$. Thus, it is necessary to further explore the microstructure and mechanical property relationship and to optimize the microstructure to improve the ductility and strength of the of Ti-22Al-25Nb-1Mo-1V-1Zr-0.2Si orthorhombic alloy.

\section{Experimental procedure}

An ingot with the nominal composition of Ti-22Al-25Nb-1Mo-1V-1Zr-0.2Si was prepared by vacuum non-consumable arc melting under vacuum atmosphere in a water-cooled copper crucible, and it was re-melted for three times in order to ensure composition homogeneity.

The ingot with $280 \mathrm{~mm}$ in diameter and $1200 \mathrm{~mm}$ in length was forged several times above and below the phase transition point, and the final forging billet size was $250 \mathrm{~mm} * 1000 \mathrm{~mm}$. The billet was divided into three parts and forged in $\mathrm{B} 2, \mathrm{a}_{2}+\mathrm{B} 2+\mathrm{O}$ and B2+O phases respectively. Samples from the as-forged specimens were solution-treated at $975^{\circ} \mathrm{C}$ for $1.5 \mathrm{~h}$ followed by water quenching, and then they were aged at $750^{\circ} \mathrm{C}$ followed by air cooling. The tensile tests at room-temperature were carried out in air by using Instron 1185 mechanical testing machine. The tensile tests at $650{ }^{\circ} \mathrm{C}$ were performed by using a MTS mechanical testing machine.

The microstructures were characterized by scanning electron microscopy (SEM, Tescan MIRA 3). The polished samples were etched by Kroll's reagent for more accurate distinguish of different phase. Image Pro Plus (IPP) software was used to count the content and size of each phase in different samples on the basis of their microstructural images. Ten images were selected for each sample at least. Fine microstructural characterization of samples was conducted using transmission electron microscopy (TEM, JEM-200CX TEM, JEOL, Japan). TEM samples were prepared by cutting slices from as forged specimens. The samples were mechanically grounded to $30-50 \mu \mathrm{m}$ in thickness by using SiC paper, and then punched into $3 \mathrm{~mm}$ discs. Finally, electrochemical polishing was used to thin the sample using a solution of $6 \%$ perchloric acid, $34 \% \mathrm{n}$-butanol, and $60 \%$ carbinol. 


\section{Results}

\section{Microstructural evolution}

Figure. 1 shows the backscatter morphology of multi-component $\mathrm{Ti}_{2} \mathrm{AlNb}$-based alloy forged in $\mathrm{B} 2$ single phase region under air cooling. Based on the imaging principle of backscattering, the microstructure of the alloy is composed of three colors contrast, hence it can be preliminarily determined that the $\mathrm{a}_{2}$ phase based on $\mathrm{Ti}_{3} \mathrm{Al}$ composition is black, the contrast of $\mathrm{B} 2$ matrix containing more beta elements is bright, and the $\mathrm{O}$ phase between $\mathrm{a}_{2}$ phase and B2 is gray. After forging in B2 single-phase zone, $O$ phase laths of different sizes and directions are distributed on the matrix, showing typical characteristics of lath structure. the volume fraction of the $\mathrm{a}_{2}$ phase, B2 and $\mathrm{O}$ was analyzed by Image-Pro Plus 6.0 image analysis software, the volume fractions of $\mathrm{O}$, $\mathrm{a}_{2}$ phase and $\mathrm{B} 2$ were $40.8 \%, 0.7 \%$ and $58.5 \%$ respectively.
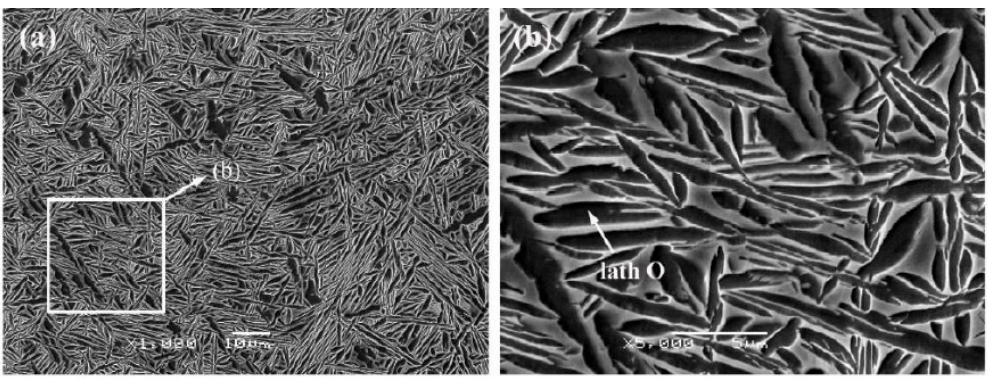

Fig.1 The microstructures of multi-component $\mathrm{Ti}_{2} \mathrm{AlNb}$ based alloy forged at $\mathrm{B} 2$ phase region: (a) low-magnification; (b) highmagnification

Figure. 2 shows the backscatter morphology of multi-component $\mathrm{Ti}_{2} \mathrm{AlNb}$-based alloy forged in $\mathrm{a}_{2}+\mathrm{B} 2+\mathrm{O}$ phase region under air cooling. It was found that the microstructures are mainly composed of equiaxed $\mathrm{a}_{2}$ phase particles, acicular $\mathrm{O}$ phase and B2 matrix, and the content of equiaxed $a_{2}$ phase is less than $30 \%$. According to the classification criteria for typical structures of $\mathrm{Ti}_{2}$ AlNb-based alloys, primary $\mathrm{a}_{2}$ phase or O-phase equiaxed particles and secondary lath are continuously distributed in the matrix, and the structure with primary $a_{2}$ phase content less than $30 \%$ is dual-microstructure. Combining with the characteristics of multi-component $\mathrm{Ti}_{2} \mathrm{AINb}$-based alloy in the three-phase zone of $\mathrm{a}_{2}+\mathrm{B} 2+\mathrm{O}$, it can be concluded that the microstructure forged at three-phase zone of $\mathrm{a}_{2}+\mathrm{B} 2+\mathrm{O}$ is dual-microstructure. Compared with the lath microstructure forging in B2 phase zone, the $\mathrm{a}_{2}$ phase is formed in the forging at $\mathrm{a}_{2}+\mathrm{B} 2+\mathrm{O}$ zone, which plays the role of pinning and restraining the growth of $\mathrm{B} 2$ grains. The acicular $O$ phase is formed in the cooling process after forging, so it is uniformly distributed in the crystal. The volume fractions of $\mathrm{O}, \mathrm{a}_{2}$ phase and B2 phase were analyzed, and the corresponding contents were $58.8 \%, 1.1 \%$ and $40.1 \%$ respectively.
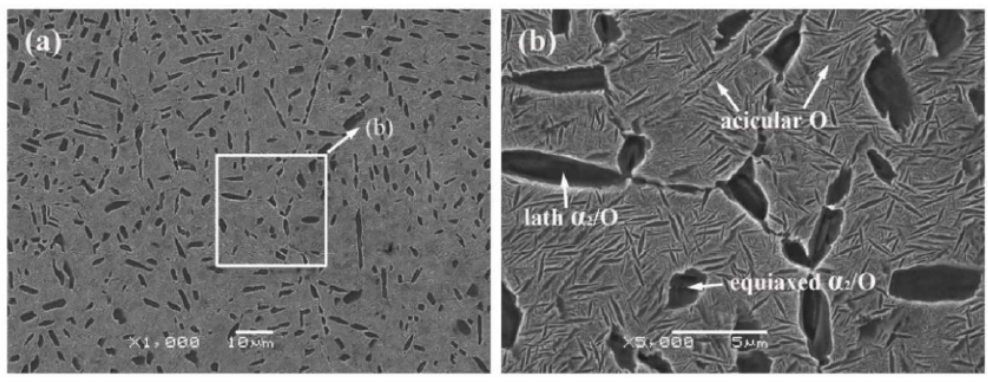

Fig.2 The microstructures of multi-component $\mathrm{Ti}_{2} \mathrm{AlNb}$ based alloy forged at $\alpha_{2}+\mathrm{B} 2+\mathrm{O}$ phase region: (a) low-magnification; (b) highmagnification
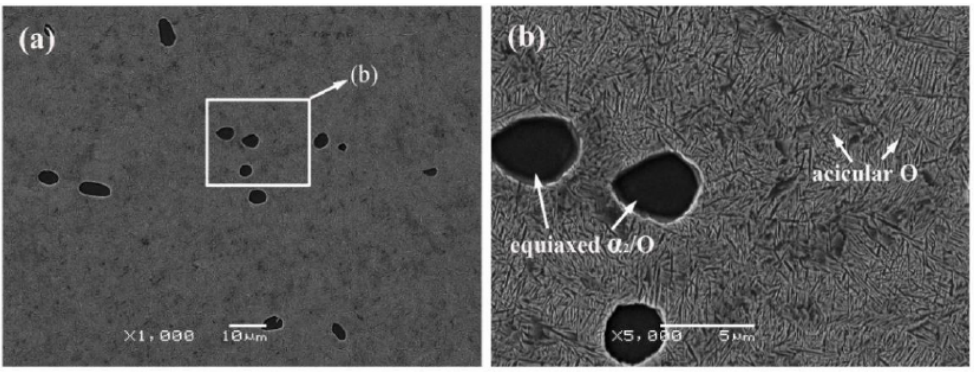

Fig.3 The microstructures of multi-component $\mathrm{Ti}_{2} \mathrm{AlNb}$ based alloy forged at $\mathrm{B} 2+\mathrm{O}$ phase region: low-magnification; (b) highmagnification 
Fig.3 shows the microstructure of the alloy forging at the B2+O two-phase region. Compared with the forging structure in three-phase zone, the equiaxed particles of $\mathrm{a}_{2} / \mathrm{O}$ phase are more uniform and the needle-like $\mathrm{O}$ phase is smaller. The volume fractions of the alloys corresponding to the three phases of $\mathrm{O}, \mathrm{a}_{2}$ and $\mathrm{B} 2$ are $68.7 \%, 1.1 \%$ and $30.2 \%$, respectively. and the volume fraction of $O$ phase increases while that of $B 2$ phase decreases.

\section{Mechanical Properties of the alloy}

Table1 shows the room and high temperature tensile properties of multi-component $\mathrm{Ti}_{2} \mathrm{AlNb}$-based alloy specimens forged in three phases and then aged at $750^{\circ} \mathrm{C}$ after heat treatment. From the test results, it can be seen that the lath structure obtained by forging and heat treatment in B2 single-phase zone shows high strength and low plasticity. The average tensile strength at room temperature is $1188 \mathrm{MPa}$, yield strength is $1134 \mathrm{MPa}$ and elongation is $2.1 \%$. The high temperature tensile strength, yield strength and elongation at $650^{\circ} \mathrm{C}$ are $950 \mathrm{MPa}, 895 \mathrm{MPa}$ and $2.9 \%$ respectively. The average tensile strength at room temperature is $1100 \mathrm{MPa}$ and the yield strength is $985 \mathrm{MPa}$, which is slightly lower than the tensile and yield strength at B2 single-phase forging. However, the elongation and cross-section shrinkage, which characterize the excellent plasticity index, are greatly increased. The elongation and cross-section shrinkage at room temperature reach $9.0 \%$ and $12 \%$. The average tensile strength and yield strength at high temperature are $910 \mathrm{MPa}$ and $822 \mathrm{MPa}$, which are also slightly lower than those forged in B2 single-phase zone, but the high temperature plastic elongation increases to $36 \%$. The strength and plasticity of dualmicrostructure forged in the $\mathrm{a}_{2}+\mathrm{B} 2+\mathrm{O}$ three-phase zone are between the equiaxed structure and the lath structure.

Table 1 Room and high temperature of tensile properties of multi-component $\mathrm{Ti}_{2} \mathrm{AINb}$ alloy under different processing

\begin{tabular}{llllll}
\hline Processing & Test temperature $/{ }^{\circ} \mathrm{C}$ & $\begin{array}{l}\text { Ultimate tensile } \\
\text { strength/ } \mathrm{MPa}\end{array}$ & Yield strength/MPa & Elongation/\% & $\begin{array}{l}\text { Reduction area/ } \\
\%\end{array}$ \\
\hline zone & Room temp & 1188 & 1134 & 2.1 & 3.2 \\
$\mathrm{~B} 2$ & $650^{\circ} \mathrm{C}$ & 950 & 895 & 2.9 & 7.4 \\
& Room temp & 1082 & 924 & 6.4 & 8.5 \\
$\alpha_{2}+\mathrm{B} 2+\mathrm{O}$ & $650^{\circ} \mathrm{C}$ & 983 & 843 & 7.5 & 12 \\
& Room temp & 1100 & 985 & 9.0 & 57 \\
$\mathrm{~B} 2+\mathrm{O}$ & $650^{\circ} \mathrm{C}$ & 910 & 822 & 36 & 57 \\
\hline
\end{tabular}

Fig.4 (a) and (b) show the fracture morphology of the lath structure obtained by forging in B2 single phase zone at room temperature. It can be seen from the figure that there is almost no necking phenomenon in the tensile fracture at room temperature. The macro surface of the fracture is vertical to the tensile stress, and the fracture surface is flat, with dark gray color and no metallic luster. Riverlike patterns can be observed in the radiation area of the fracture surface, which shows obvious brittle fracture characteristics. The results are consistent with the plasticity index of the alloy itself.
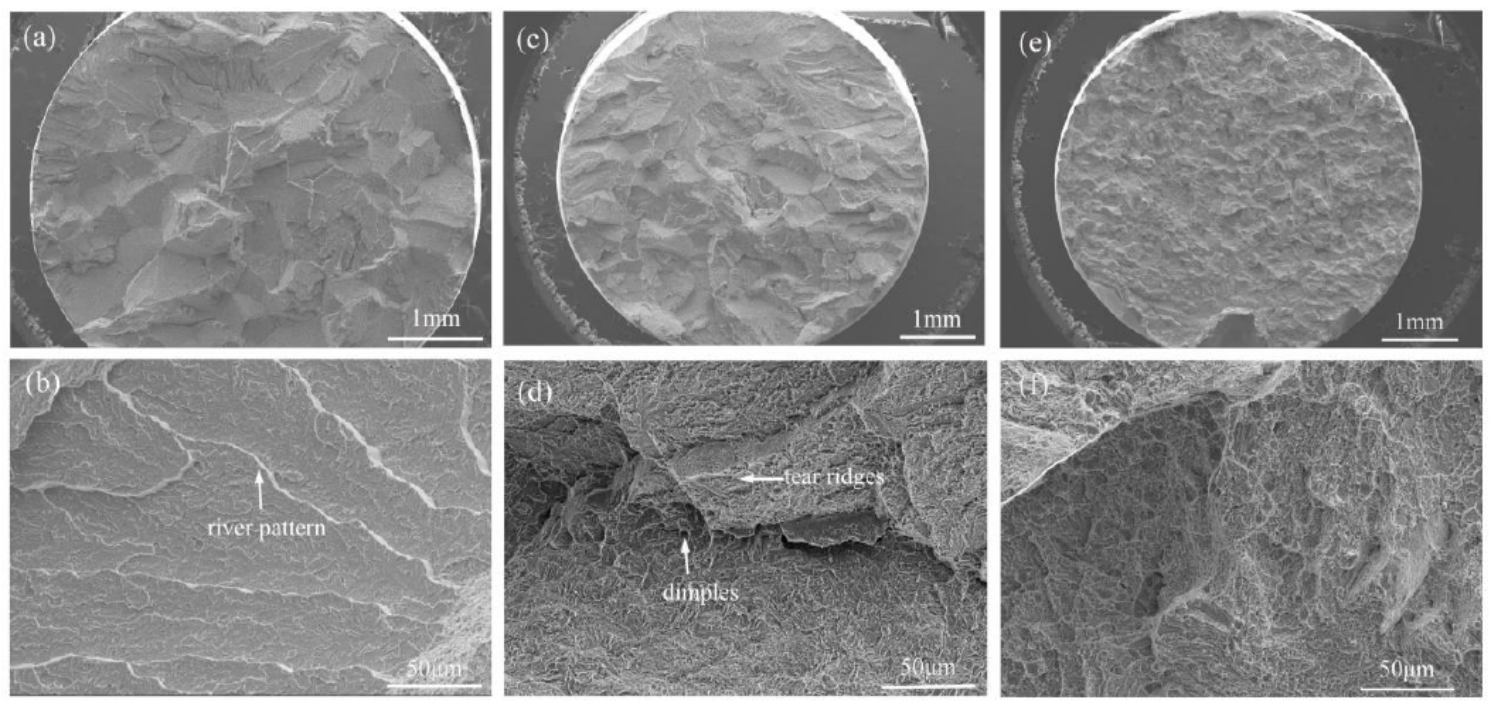

Fig.4 Room temperature tensile fractographs of multi-component $\mathrm{Ti}_{2} \mathrm{AINb}$ based alloy: (a), (c) and (e) macro-fractograph; (b) (b), (d) and

(f)micro-fractograph 
Fig.4 (c) and (d) show the fracture morphology of the dual structure obtained by forging in $\mathrm{a}_{2}+\mathrm{B} 2+\mathrm{O}$ phase zone at room temperature. Compared with the lath structure obtained by forging in B2 single-phase zone, the effect of $a_{2}$ on grain boundary pinning during forging in $\mathrm{a}_{2}+\mathrm{B} 2+\mathrm{O}$ three-phase zone makes the forged grains fine and the room temperature plasticity of the dual-phase structure slightly increased. Fig.4 (e) and (f) show the fracture morphology of equiaxed $\mathrm{Ti}_{2} \mathrm{AlNb}^{\mathrm{N}}$-based alloy forged in $\mathrm{B} 2+\mathrm{O}$ phase region after tension at room temperature, which is showed quasi-cleavage fracture characteristics due to Fiber region, radiation region and shear lip region of the fracture.
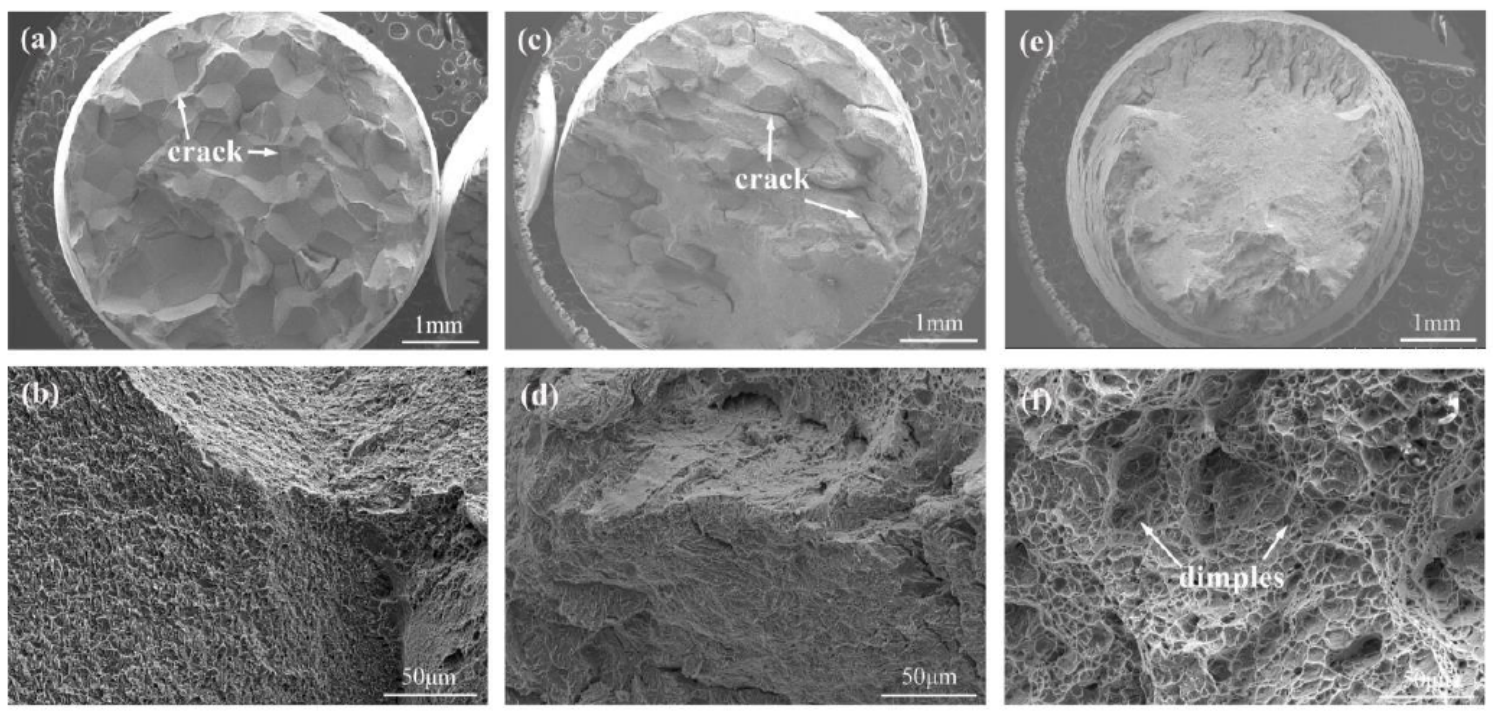

Fig.5 High temperature tensile fractographs of multi-component $\mathrm{Ti}_{2} \mathrm{AINb}$ based alloy: (a), (c) and (e) macro-fractograph; (b) (b), (d) and (f)micro-fractograph

Fig. 5 shows high temperature tensile fracture morphologies of multi-component $\mathrm{Ti}_{2} \mathrm{AlNb}_{\mathrm{N}}$-based alloy bars forged in three phases. Fig. 5(a) and (b) are the fracture morphology of high-temperature tensile lath structure obtained by forging in B2 singlephase region. It can be seen from the figure that there is almost no necking phenomenon in the high-temperature tensile fracture, and the fracture morphology is crystalline ice sugar block, and there are micro-cracks along the grain boundary.

Fig.5(e) is the macro-fracture morphology of equiaxed structure obtained by forging in B2+O phase region after high temperature tension. From the graph, it can be seen that the fracture surface is cup-cone shape, the fracture height is different, there is obvious plastic deformation necking characteristics. Fig.5(f) is the micro-morphology of the fibrous zone of the fracture. The fibrous zone, radiation zone and shear lip zone of the fracture are also obvious. The fibrous zone of the fracture is large, and the fracture is filled with dimples of different depths. Compared with the fracture morphology of the dual microstructure (Fig.5(c), 5(d)), there are no micro-cracks and deep dimples in the fracture surface of the forged structure in the zone of B2+O, and the fracture mode is ductile fracture. The results show that the equiaxed structure obtained by forging in $\mathrm{B} 2+\mathrm{O}$ phase region has good plasticity at high temperature, which is consistent with the experimental results of high elongation index and high section shrinkage of alloy at high temperature (Table 5-1).

\section{Discussions}

The mechanical properties of $\mathrm{Ti}_{2} \mathrm{AlNb}$-based alloys under different microstructures show that the properties of $\mathrm{Ti}_{2} \mathrm{AlNb}$ based alloys are basically the same as those of other intermetallic, showing the characteristics of high strength and low plasticity. However, strong plasticity varies with different microstructures. The tensile strength of lath structure is high, the plasticity of equiaxed structure is good, and the strength-plasticity of duplex structure is between the two. For the three kinds of structures, the main influence is the difference of forging temperature. lath microstructure is obtained by forging at higher temperature. The grain size of B2 obtained by forging at higher temperature is the largest. While that the equiaxed microstructure is the smallest. According to the principle of fine grain strengthening, equiaxed structure should have high yield strength theoretically, but the result is contrary to the conclusion. The volume fraction of B2 phase in lath microstructure is the highest, while that of B2 phase as plastic phase can move and slip more. Therefore, the lath microstructure should have high plasticity index, but the result is just the opposite. It is shown that besides the grain size, phase type and phase content of B2, the micro-variables such as morphology and thickness of various phases in multi-component $\mathrm{Ti}_{2} \mathrm{AlNb}$-based alloys need to be taken into account. Therefore, it is necessary to combine fracture mode analysis. 

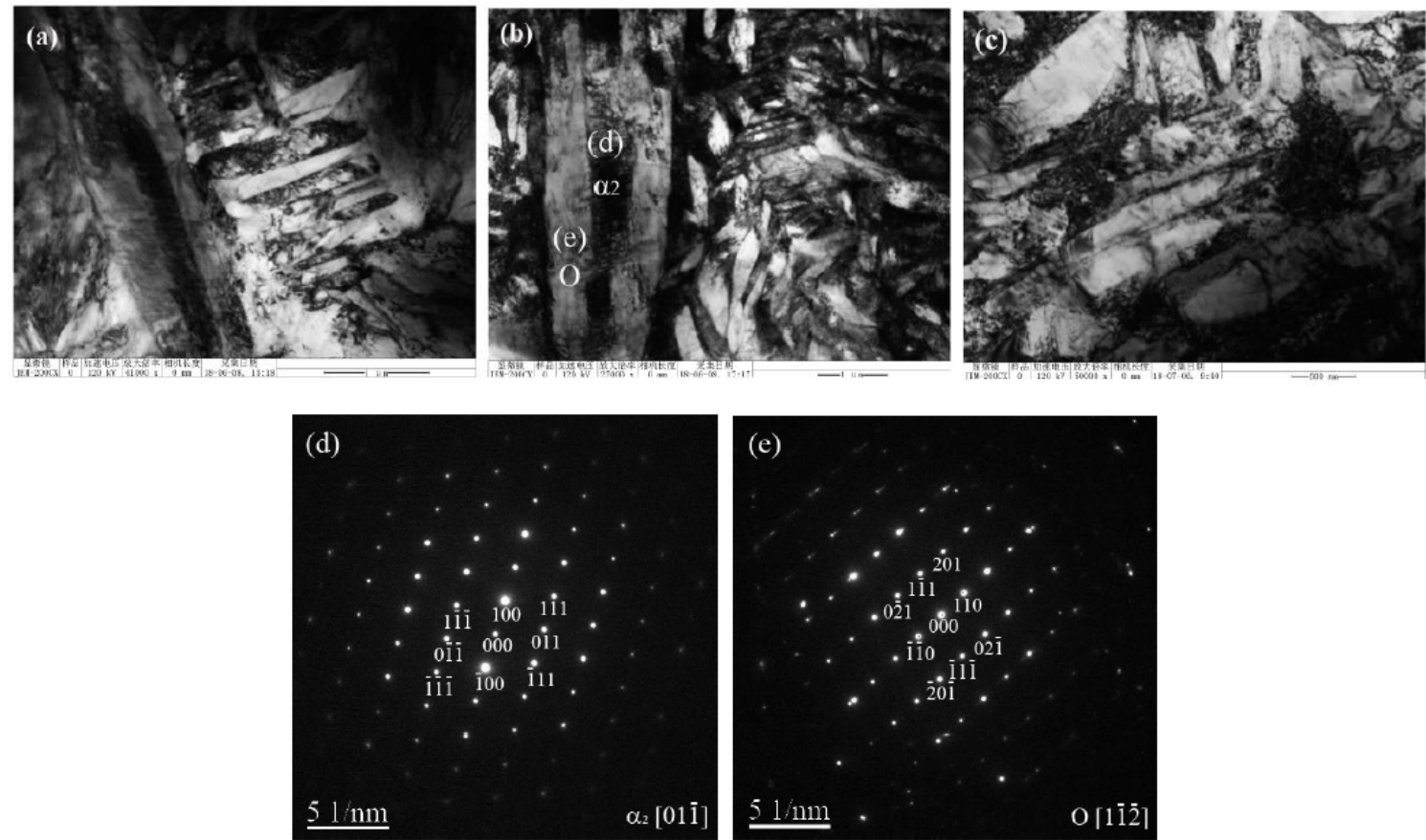

Fig.6 Microstructure and diffraction pattern of as forged multi-component $\mathrm{Ti}_{2} \mathrm{AINb}$ based alloy: (a) TEM micrograph of lath

microstructure; (b) TEM micrograph of dual microstructure; (c) TEM micrograph of equiaxed microstructure; (d) $\alpha_{2}$ phase; (e) $O$ phase

Fig.6(a) and (b) show the transmission morphology of lath and dual microstructures. It can be seen from the figure that the long cellular phase is covered in the thick lath. Diffraction analysis shows that the long cellular phase is $a_{2}$ phase, while the outer thick lath is $\mathrm{O}$ phase. The width of the $\mathrm{a}_{2} / \mathrm{O}$ lath is about $1.2 \mathrm{um}$, and the dislocation density in the lath is very low. Fig.6(c) is TEM with equiaxed structure. Compared with lath and dual microstructure, equiaxed structure is mainly composed of lath $\mathrm{O}$ phase and $B 2$ phase. There is no $a_{2} / O$ phase in TEM, and the width of $O$ phase is about $0.5 \mathrm{um}$, the dislocation density is higher.
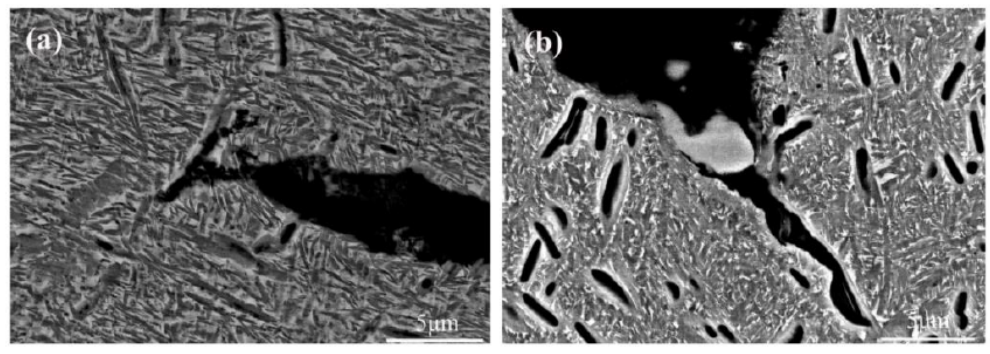

Fig.7 Tensile Microstructure of lath and dual microstructure of multi-component $\mathrm{Ti}_{2} \mathrm{AlNb}$ based alloy: (a) lath microstructure; (b) dual microstructure

From the analysis of the tensile fracture in Fig7, it is found that the tensile fracture is initiated with the coarsening of $a_{2} / \mathrm{O}$, and the fine O-phase lath can hinder the crack propagation, thus improving the strength of the alloy. Continuous crack propagation will intersect with many spiral dislocations to form a step with sufficient height, which will become a river pattern visible under the electron microscope, and result to the plasticity of the alloy is poor. Due to the fine and uniform size of $O$ phase and high dislocation density, the equiaxed structure exhibits excellent plasticity in tension.

\section{Conclusion}

The lath structure was obtained by forging in B2 single-phase zone, which was composed of lath-like $a_{2} / O$ phase, needle-like $\mathrm{O}$ phase and B2 matrix. Dual microstructure was obtained by forging in $\mathrm{a}_{2}+\mathrm{O}+\mathrm{B} 2$ three-phase zone, which consisted of primary equiaxed $\mathrm{a}_{2} / \mathrm{O}$ phase, lath-like $\mathrm{O}$ phase, needle-like $\mathrm{O}$ phase and B2 matrix. The equiaxed micro-structure was obtained by forging in O+B2 phase zone, which is mainly composed of primary equiaxed O phase and B2 matrix. Under the same heat treatment regime, the tensile properties of lath microstructure at room temperature and high temperature show the characteristics of high strength and low plasticity. The tensile strength at room temperature is $1188 \mathrm{MPa}$, and the tensile strength at high temperature is $950 \mathrm{MPa}$. The equiaxed structure shows the characteristics of low plasticity and high strength, with 
elongation of $9.0 \%$ and high temperature elongation of $36 \%$. The strength and plasticity of dual microstructure is between that of lath and equiaxed structure.

\section{Acknowledgments}

This work was financially supported by the National Natural Science Foundation of China (No. 51601146) and the China postdoctoral Science Foundation (No. 2017M613234).

\section{References}

[1] BANERJEE D, GOGIA A K, NANDI T K, JOSHI V A. A new ordered orthorhombic phase in a Ti ${ }_{3}$ Al-Nb alloy. Acta Metallurgical, 1988, 36 (4): 871-882.

[2] DEY S R, SUWAS S, FUNDENBERGER J J, RAY R K. Evolution of crystallographic texture and microstructure in the orthorhombic phase of a two- phase alloy Ti-22Al-25Nb. Intermetallics, 2009, 17 (8): 622-633.

[3] TANG F, EMURA S, HAGIWARA M. Tensile properties of Tungsten-modified orthorhombic Ti-22Al-20Nb-2W alloy . Scripta Materialia, 2001, 44 (4): 671-676.

[4] MAO Y, LI S Q, ZHANG J W, PENG J H, ZOU D X, ZHONG Z Y. Microstructure and tensile properties of orthorhombic Ti-Al-Nb-Ta alloys. Intermetallics, 2000, 8 (5-6): 659-662.

[5] D. Banerjee, A.K. Gogia, T.K. Nandi, V.A. Joshi. A new ordered orthorhombic phase in a Ti ${ }_{3} \mathrm{Al}-\mathrm{Nb}$ alloy. Acta Metallurgica, 1988; 36 (4): 871.

[6] J. Kumpfert. Intermetallic alloys based on orthorhombic titanium aluminide. Advanced Engineering Materials, 2001; 3 (11): 851.

[7] A.K. Gogia, T.K. Nandy, D. Banerjee, T. Carisey, J.L. Strudel, J.M. Franchet. Microstructure and mechanical properties of orthorhombic alloys in the Ti-Al-Nb system. Intermetallics, 1998; 6 (7): 741.

[8] H.T. Kestner-Weykamp, C.H. Ward, T.F. Broderick, M.J. Kaufman. Microstructures and phase relationships in the Ti3Al+Nb system. Scripta Metallurgica, 1989; 23 (10): 1697.

[9] J.-L. Zhang, H.-Z. Guo, H.-Q. Liang, Hot deformation behavior and process parameter optimization of Ti22Al25Nb using processing map, Rare Metals, 35 (2016) 118-126.

[10] H. Wu, P. Zhang, H. Zhao, L. Wang, A. Xie. Effect of different alloyed layers on the high temperature oxidation behavior of newly developed Ti2AINb-based alloys. Applied Surface Science, 2011; 257 (6): 1835.

[11] R.G. Rowe, D.G. Konitzer, A.P. Woodfield, J.C. Chesnutt. Tensile and creep behavior of ordered orthorhombic Ti2A1Nb-based alloys. MRS Proceedings, 2011; 213. [12] Yong-Sheng He, Rui Hu, Wen-zhong Luo, Tao He, Xiang-Hong Liu. Oxidation behavior of a novel multi-element alloyed Ti2AINb-based alloy in the temperature range of $650^{\circ} \mathrm{C}$ to $850^{\circ} \mathrm{C}$. Rare Metals. $2018,37(10): 838-845$

[13] Yong-Sheng He, Rui Hu, Wen-zhong Luo, Tao He, Yun-Jin Lai, Yu-Jun Du, Xiang-Hong Liu. Microstructural evolution and creep deformation behavior of a novel Ti-22Al-25Nb-1Mo-1V-1Zr-0.2Si (at, \%) orthorhombic alloy. Transaction of Nonferrous Metals Society of China. 2019, 29(2): 313-321.

[14] C.J. Boehlert, B.S. Majumdar, V. Seetharaman, D.B. Miracle. Part. The Microstructural Evolution in Ti-Al-Nb O+BCC Orthorhombic Alloys. Metallurgical and Materials Transactions A. 1999, 30(9): 2305-2323

[15] C. J. Boehlert, B. S. Majumdar, V. Seetharaman, D. B. Miracle, and R. Wheeler: Structural Intermetallics 1997, M. V. Nathal, R. Darolia, C. T. Liu, P. L. Martin, D. B. Miracle, R. Wagner, and M. Yamaguchi, eds., TMS, Warrendale, PA. 1997, 795-804

[16] C.J. Cowen, C.J. Boehlert. Microstructure, Creep, and Tensile Behavior of a Ti-21Al-29Nb (at. \%) Orthorhombic+B2 Alloy. Intermetallics. 2006, 14(4): 412-422 
* Corresponding author. Tel./Fax: +86 2988491764.

E-mail address: heysh1210@126.com (Y.S. He). 